\title{
Synovial fluid biomarkers associated with osteoarthritis severity reflect macrophage and neutrophil related inflammation
}

\author{
Collin A. Haraden ${ }^{1 \dagger}$, Janet L. Huebner ${ }^{1 \dagger}$, Ming-Feng Hsueh', Yi-Ju Li ${ }^{1,2}$ and Virginia Byers Kraus ${ }^{1,3^{*}}$ (D)
}

\begin{abstract}
Background: To identify a synovial fluid (SF) biomarker profile characteristic of individuals with an inflammatory osteoarthritis $(\mathrm{OA})$ endotype.
\end{abstract}

Methods: A total of 48 knees (of 25 participants) were characterized for an extensive array of SF biomarkers quantified by Rules Based Medicine using the high-sensitivity multiplex immunoassay, Myriad Human InflammationMAP® 1.0, which included 47 different cytokines, chemokines, and growth factors related to inflammation. Multivariable regression with generalized estimating equations (GEE) and false discovery rate (FDR) correction was used to assess associations of SF RBM biomarkers with etarfolatide imaging scores reflecting synovial inflammation; radiographic knee OA severity (based on Kellgren-Lawrence $(K L)$ grade, joint space narrowing, and osteophyte scores); knee joint symptoms; and SF biomarkers associated with activated macrophages and knee OA progression including CD14 and CD163 (shed by activated macrophages) and elastase (shed by activated neutrophils).

Results: Significant associations of SF biomarkers meeting FDR $<0.05$ included soluble (s)VCAM- 1 and MMP-3 with synovial inflammation (FDR-adjusted $p=0.025$ and $1.06 \times 10^{-7}$ ); sVCAM-1, sICAM-1, TIMP-1, and VEGF with radiographic OA severity $\left(p=1.85 \times 10^{-5}\right.$ to $\left.3.97 \times 10^{-4}\right)$; and VEGF, MMP-3, TIMP-1, SICAM-1, sVCAM-1, and MCP-1 with OA symptoms ( $p=2.72 \times 10^{-5}$ to 0.050 ). All these SF biomarkers were highly correlated with macrophage markers CD163 and CD14 in SF ( $r=0.43$ to 0.90, FDR < 0.05); all but MCP-1 were also highly correlated with neutrophil elastase in SF $(r=0.62$ to 0.89 , FDR < 0.05$)$.

Conclusions: A subset of six SF biomarkers was related to synovial inflammation in OA, as well as radiographic and symptom severity. These six OA-related SF biomarkers were specifically linked to indicators of activated macrophages and neutrophils. These results attest to an inflammatory OA endotype that may serve as the basis for therapeutic targeting of a subset of individuals at high risk for knee OA progression.

Trial registration: Written informed consent was received from participants prior to inclusion in the study; the study was registered at ClinicalTrials.gov (NCT01237405) on November 9, 2010, prior to enrollment of the first participant.

Keywords: Osteoarthritis, Joint pain, Macrophage, Neutrophil, Inflammation, Biomarker, Knee, Severity, Radiograph

\footnotetext{
* Correspondence: vbk@duke.edu

${ }^{\dagger}$ Collin A. Haraden and Janet L. Huebner are co-first authors.

${ }^{1}$ Duke Molecular Physiology Institute, Duke University School of Medicine,

Box 104775, 300 North Duke St, Durham, NC 27701, USA

${ }^{3}$ Department of Medicine, Duke University School of Medicine, Durham, NC, USA

Full list of author information is available at the end of the article
}

(c) The Author(s). 2019 Open Access This article is distributed under the terms of the Creative Commons Attribution 4.0 International License (http://creativecommons.org/licenses/by/4.0/), which permits unrestricted use, distribution, and reproduction in any medium, provided you give appropriate credit to the original author(s) and the source, provide a link to the Creative Commons license, and indicate if changes were made. The Creative Commons Public Domain Dedication waiver (http://creativecommons.org/publicdomain/zero/1.0/) applies to the data made available in this article, unless otherwise stated. 


\section{Background}

Although the role of inflammation in osteoarthritis (OA) has been heavily debated, cumulative evidence from ultrasound and magnetic resonance imaging (MRI) demonstrates inflammation in the majority of individuals with radiographic knee OA [1-4]. Moreover, inflammation in the form of MRI effusion or Hoffa's fat pad synovitis predict increased risk of incident radiographic knee OA [5, 6]. Using 99mTc-etarfolatide nuclear imaging, we have detected a high frequency of folate receptorpositive cells $(\mathrm{FR}+)$, representing activated macrophages [7] and neutrophils [8], in knee OA.

Both macrophages and neutrophils respond to and perpetuate local inflammation. In response to damageassociated molecule patterns (DAMPs) and inflammatory cytokines, macrophages can become activated in the joint organ and modulate the local cytokine, growth factor, and matrix metalloproteinase (MMP) environment $[9,10]$. Neutrophils secrete a number of proteinases including elastase [11] capable of degrading many targets including elastin, collagens, and proteoglycans [12]. In addition, neutrophil elastase can upregulate the expression of proteinase-activated receptors (PARs) and activate them though cleavage [13]. When activated, PARs perpetuate synovitis and cartilage loss and cause hyperalgesia and osteophyte formation $[14,15]$.

We recently discovered that synovial fluid (SF) biomarkers CD14 and CD163, soluble forms of macrophage cell surface markers, and SF elastase, secreted by neutrophils $[8,16]$, function as quantitative traits of the etarfolatide-positive phenotype and predict knee OA progression over 3 years $[8,16]$. Using the SF and plasma samples from individuals with knee OA, our goal in this substudy was to investigate the association of an extensive array of SF biomarkers with knee OA inflammation based on etarfolatide phenotyping, radiographic manifestations of knee OA, and OA symptoms. Patients were recruited for the original study on evidence of radiographic OA and symptoms and not inflammatory OA clinical signs. Thus, this substudy was designed to evaluate inflammation in "typical" OA joints. We hypothesized that the synovial fluid biomarkers associated with etarfolatide imaging and knee radiographic OA severity would provide a molecular biological profile for identifying the subset of subjects with an inflammatory OA endotype [17].

\section{Patients and methods}

\section{Study description}

This is a novel substudy of an investigator-initiated single-center clinical trial conducted at Duke University Medical Center performed as previously described [7] and with authorization from the Food and Drug Administration (IND 108,677). The study was registered at
ClinicalTrials.gov (NCT01237405) prior to enrollment of the first participant. Participants $\geq 18$ years old were recruited on the basis of radiographic OA (KellgrenLawrence [18] grade 1-4 severity) in at least one knee and knee pain in the index knee on most days of any 1 month in the last year [19]. A total of 25 participants were enrolled. Exclusion criteria were as previously described [7]. This clinical investigation was conducted according to the Declaration of Helsinki principles, with the approval of the Duke University Medical Center Institutional Review Board. Written informed consent was received from participants prior to inclusion in the study.

\section{Imaging}

Knee radiographs $(n=50)$ of both knees of 25 patients were obtained as previously described using an optimal and standardized method with the SynaFlexer ${ }^{\mathrm{mm}}$ frame [20]. Radiographs were graded blinded to other imaging and clinical data by the consensus of two experienced readers with high inter-rater reliability as previously described [21]. Radiographs were scored for KellgrenLawrence (KL) [18] grade (0-4), joint space narrowing (JSN, 0-3), and osteophyte severity (OST, 0-3) using a standard atlas [22]. All 25 individuals also underwent Etarfolatide imaging of both knees and the whole body as previously described with high intra-rater reliability of scoring $(\kappa=0.68-0.90)$ [7]. For these analyses, severity of synovitis due to the presence of cells positive for folate receptor, reflecting both activated macrophages and neutrophils, was quantified by summing synovial etarfolatide scores for medial and lateral compartments of the knee.

\section{Clinical symptoms}

All 50 knees were scored semi-quantitatively (normal/ none 0 , mild 1 , moderate 2 , or severe 3 ) for self-reported intensity of joint pain ascertained by the NHANES I criterion [19] (pain, aching or stiffness (PAS) on most days of any 1 month in the last year).

\section{Biospecimen collection}

SF was collected from 48 knees either directly $(n=28)$ or by small volume $(10 \mathrm{ml})$ saline lavage $(n=20)$ when direct aspiration failed. Two patients refused joint aspirations of their second knee. The dilution factor of SF obtained by small volume saline lavage was determined, and corresponding biomarker concentrations were corrected using a previously established urea-based methodology [23]. Whole blood was obtained immediately after SF aspiration using Truculture Null (782-001086, RBM) tubes with subsequent manual separation of plasma supernatants from cells using valve filter Seraplas ${ }^{\oplus}$ V11 (53.677, Sarstedt). All samples were stored at $-80^{\circ} \mathrm{C}$ until analysis. 


\section{Biomarker quantification}

Biomarkers in SF and plasma were quantified by Rules Based Medicine (RBM; Austin, TX) using the highsensitivity multiplex immunoassay Myriad Human InflammationMAP ${ }^{\circ}$ 1.0. Measured biomarkers included 47 different cytokines, chemokines, and growth factors related to inflammation. For purposes of statistical analyses, biomarkers were excluded if $>25 \%$ of the samples had out-of-range low values; excluded biomarkers were brain-derived neurotropic factor (BDNF), C-reactive protein (CRP), eotaxin-1, granulocyte macrophage colony-stimulating factor (GM-CSF), interferon gamma (IFN), interleukin-1 beta (IL-1 $\beta$ ), interleukin-2 (IL-2), interleukin-3 (IL-3), interleukin-4 (IL-4), interleukin-5 (IL-5), interleukin-6 (IL-6), interleukin-7 (IL-7), interleukin-8 (IL-8), interleukin-10 (IL-10), interleukin15 (IL-15), interleukin-17 (IL-17), interleukin-18 (IL-18), interleukin-23 (IL-23), interleukin-12 subunit p40 (IL12p40), interleukin-12 subunit p70 (IL-12p70), macrophage inflammatory protein-1 alpha (MIP- $1 \alpha)$, macrophage inflammatory protein-1 beta (MIP-1 $\beta$ ), matrix metalloproteinase-2 (MMP-2), T-cell specific protein (RANTES), tumor necrosis factor alpha (TNF $\alpha$ ), tumor necrosis factor beta (TNF $\beta$ ), tumor necrosis factor receptor 1 (TNFR1), and von Willebrand factor (vWF).
A total of 17 SF biomarkers met inclusion criteria for statistical analysis. For retained biomarkers, out-of-range low concentrations were imputed as $1 / 2$ the lower limit of detection (LLOD; $n=34$ concentrations representing 4\% of total determinations); out-of-range high values were imputed as twice the upper limit of detection (ULOD; $n=1$ concentration representing $0.1 \%$ of total determinations). Intra- and inter-assay coefficients of variance for the retained biomarkers, as determined by RBM, were $<7 \%$ and $<15 \%$, respectively (Table 1 ). The mean and interquartile range of SF and plasma biomarker concentrations and the number outside limits of detection are reported in Table 1.

\section{Statistical analysis}

We evaluated the association of SF and plasma biomarker concentrations with synovial inflammation (based on Etarfolatide imaging), radiographic OA severity and OA symptoms. Due to the inclusion of measurements from two knees of each patient, generalized estimating equations (GEE) were used to account for within-subject correlation using exchangeable variancecovariance matrix. The GEE model includes the main predictor of interest (the biomarker), age, gender, and body mass index (BMI) for each outcome of interest.

Table 1 Descriptive statistics for included biomarkers

\begin{tabular}{|c|c|c|c|c|c|c|c|c|c|c|c|c|}
\hline \multirow[b]{2}{*}{ Biomarker } & \multicolumn{4}{|c|}{ Synovial fluid } & \multicolumn{4}{|c|}{ Plasma } & \multirow[b]{2}{*}{ LLOD } & \multirow[b]{2}{*}{ Unit } & \multirow[b]{2}{*}{$\begin{array}{l}\text { Intra-assay } \\
\text { CV (\%) }\end{array}$} & \multirow[b]{2}{*}{$\begin{array}{l}\text { Inter- assay } \\
\text { CV (\%) }\end{array}$} \\
\hline & $N$ & $\begin{array}{l}N \text { outside } \\
\text { LOD }\end{array}$ & Mean & IQR & $N$ & $\begin{array}{l}N \text { outside } \\
\text { LOD }\end{array}$ & Mean & IQR & & & & \\
\hline$\overline{A 2 M}$ & 48 & 0 & 0.17 & 0.11 & 25 & 0 & 0.42 & 0.11 & 0.051 & $\mathrm{mg} / \mathrm{mL}$ & 7.26 & 13.75 \\
\hline AAT & 48 & 0 & 0.53 & 0.46 & 25 & 0 & 1.01 & 0.23 & 0.0065 & $\mathrm{mg} / \mathrm{mL}$ & 4.93 & 9.33 \\
\hline $\mathrm{B} 2 \mathrm{M}$ & 47 & 1 & 1.10 & 0.90 & 25 & 0 & 0.76 & 0.27 & 0.15 & $\mu \mathrm{g} / \mathrm{mL}$ & 3.83 & 6.33 \\
\hline $\mathrm{C} 3$ & 47 & 1 & 0.13 & 0.14 & 25 & 0 & 0.57 & 0.18 & 0.00065 & $\mathrm{mg} / \mathrm{mL}$ & 5.87 & 7.33 \\
\hline Factor7 & 44 & 4 & 66.29 & 74.91 & 25 & 0 & 484.88 & 143.00 & 5.60 & $\mathrm{ng} / \mathrm{mL}$ & 3.13 & 8.00 \\
\hline Fibrinogen & 44 & 4 & 0.08 & 0.08 & 25 & 0 & 3.69 & 1.33 & 0.0056 & $\mathrm{mg} / \mathrm{mL}$ & 5.47 & 10.67 \\
\hline FRTN & 48 & 0 & 271.66 & 229.63 & 24 & 1 & 41.14 & 41.00 & 6.23 & $\mathrm{ng} / \mathrm{mL}$ & 5.67 & 11.33 \\
\hline sICAM-1 & 46 & 2 & 21.55 & 20.52 & 25 & 0 & 55.30 & 17.50 & 4.78 & $\mathrm{ng} / \mathrm{mL}$ & 3.60 & 8.33 \\
\hline IL-1ra & 44 & 4 & 273.29 & 184.00 & 25 & 0 & 278.08 & 332.00 & 250.00 & $\mathrm{pg} / \mathrm{mL}$ & 4.87 & 7.67 \\
\hline MCP-1 & 46 & 2 & 218.52 & 195.96 & 25 & 0 & 381.98 & 166.00 & 9.56 & $\mathrm{pg} / \mathrm{mL}$ & 3.53 & 6.00 \\
\hline MMP-3 & 45 & 3 & $1.16 \times 10^{6}$ & $5.75 \times 10^{5}$ & 25 & 0 & $1.22 \times 10^{4}$ & $5.30 \times 10^{3}$ & $5.07 \times 10^{3}$ & $\mathrm{pg} / \mathrm{mL}$ & 3.87 & 8.67 \\
\hline MMP-9 & 43 & 5 & 30.50 & 15.1 & 23 & 2 & 15.00 & 6.50 & 41.4 & $\mathrm{ng} / \mathrm{mL}$ & 4.53 & 8.33 \\
\hline SCF & 45 & 3 & 198.56 & 77.00 & 25 & 0 & 94.75 & 38.50 & 195.6 & $\mathrm{pg} / \mathrm{mL}$ & 3.47 & 6.67 \\
\hline TIMP-1 & 48 & 0 & 177.44 & 201.05 & 25 & 0 & 37.14 & 16.80 & 9.575 & $\mathrm{ng} / \mathrm{mL}$ & 3.80 & 10.00 \\
\hline sVCAM-1 & 45 & 3 & 292.10 & 290.80 & 25 & 0 & 282.36 & 90.00 & 4.265 & $\mathrm{ng} / \mathrm{mL}$ & 6.60 & 14.00 \\
\hline VDBP & 47 & 1 & 65.15 & 47.27 & 25 & 0 & 126.89 & 73.70 & 0.635 & $\mu \mathrm{g} / \mathrm{mL}$ & 3.60 & 9.67 \\
\hline VEGF & 46 & 2 & 778.06 & 873.36 & 25 & 0 & 188.80 & 45.00 & 18.14 & $\mathrm{pg} / \mathrm{mL}$ & 4.13 & 8.00 \\
\hline
\end{tabular}

Biomarkers listed yielded measurable values for $\geq 75 \%$ of samples

Abbreviations: $L O D$ limit of detection, $I Q R$ interquartile range, $L L O D$ lower limit of detection, CV coefficient of variation, $A 2 M$ alpha-2-macroglobulin, $A A T$ alpha-1antitrypsin, B2M beta-2-microglobulin, C3 complement C3, FRTN ferritin, s/CAM-1 soluble intercellular adhesion molecule 1, IL-1ra interleukin-1 receptor antagonist, MCP-1 monocyte chemotactic protein 1, MMP-3 matrix metalloproteinase-3, MMP-9 matrix metalloproteinase-9, SCF stem cell factor, TIMP-1 tissue inhibitor of metalloproteinases 1, sVCAM-1 soluble vascular cell adhesion molecule-1, VDBP vitamin D-binding protein, VEGF vascular endothelial growth factor 
False discovery rate (FDR) was computed using methodology described by Benjamini and Hochberg [24]. Significant results were determined based on an FDRadjusted $p$ value $\leq 0.05$. Significant SF RBM biomarkers from these analyses were further evaluated for correlation with SF CD14, SF CD163, and SF neutrophil elastase (measured previously on these samples as described $[8,16]$ ) using the Bland and Altman method (rmcorr package in R) to compute repeated measures correlation coefficients [25]. For the correlation between SF and plasma biomarkers, we averaged SF biomarkers across both knees before computing Spearman correlations. These GEE, Bland and Altman correlations, and Spearman analyses were performed using R (https://www.rproject.org/). To determine if SF biomarker concentrations were statistically significantly higher than plasma (and therefore potentially of joint tissue origin), the plasma concentrations and the average SF biomarker concentration of both knees were evaluated with the one-sided Wilcoxon signed-rank test using JMP $^{\circ}$ Pro, Version 13 (SAS Institute Inc., Cary, NC). A protein functional association network plot was generated using STRING v10.5 database (http://string-db.org) [26].

\section{Results}

\section{Etarfolatide scan cohort}

Participants $(n=25)$ were of mean age $62.4 \pm 15.8$ years (range 30-89), of mean BMI $29.2 \pm 4.8 \mathrm{~kg} / \mathrm{m} 2$ (range $22.5-38.4)$, and $72 \%$ female. The majority (76\%) of participants had moderate to severe bilateral radiographic knee OA with $24 \% \mathrm{KL}$ grade $1,58 \% \mathrm{KL}$ grade $2-3$, and $18 \%$ KL grade 4.
Association of synovial fluid biomarkers with severity of $\mathrm{OA}$ inflammation, structural features, and symptoms Of the 17 biomarkers included for statistical analyses, MMP-3 and sVCAM-1 were associated with knee inflammation as assessed by etarfolatide imaging (FDR $<0.05$ ); sICAM-1 and TIMP-1 were marginally associated with inflammation (FDR $=0.090,0.097$ ). Five biomarkers (MMP3, sVCAM-1, sICAM-1, TIMP-1, and VEGF) were associated with radiographic features of OA (FDR $<0.05)$. These same five biomarkers plus MCP-1 were statistically significantly associated with OA symptoms (FDR <0.05) (Table 2). Interestingly, MMP-3 was associated with JSN severity while sVCAM-1 was associated with both JSN and OST severity. Although SF VEGF was associated with both structural and symptom severity of OA (KL, JSN, OST, and OA symptom scores), it was not associated with inflammation as reflected by etarfolatide scores. MCP-1 was associated only with symptom severity.

\section{Correlations of synovial fluid biomarker concentrations with macrophage and neutrophil specific biomarkers} SF sVCAM-1, MMP-3, sICAM-1, TIMP-1, VEGF, and MCP-1 all correlated with markers specific for neutrophils (SF neutrophil elastase) and/or macrophages (SF CD14 and SF CD163) previously shown to predict knee OA progression $[8,16]$ (Table 3). These results suggest that this six-member panel of biomarkers reflects both macrophage- and neutrophil-mediated inflammation.

\section{Assessment of potential origin of biomarkers}

Although plasma biomarker concentrations were not associated with any OA severity outcome, concentrations

Table 2 Synovial fluid biomarkers associated with features of osteoarthritis (inflammation, radiographic, and symptom severity)

\begin{tabular}{llllll}
\hline & Etarfolatide imaging & Radiographic severity & & \multicolumn{2}{l}{ Symptom severity } \\
\cline { 2 - 6 } & Synovial inflammation & $\mathrm{KL}$ & JSN & OST & PAS \\
\cline { 2 - 6 } Biomarker & $\begin{array}{l}\text { Est. } \times 10^{-2}(95 \% \mathrm{Cl}) \\
(\mathrm{pval})\end{array}$ & $\begin{array}{l}\text { Est. } \times 10^{-2}(95 \% \mathrm{Cl}) \\
(\mathrm{pval})\end{array}$ & $\begin{array}{l}\text { Est. } \times 10^{-2}(95 \% \mathrm{Cl}) \\
(\mathrm{pval})\end{array}$ & $\begin{array}{l}\text { Est. } \times 10^{-2}(95 \% \mathrm{Cl}) \\
(\mathrm{pval})\end{array}$ & $\begin{array}{l}\text { Est. } \times 10^{-2}(95 \% \mathrm{Cl}) \\
(\mathrm{pval})\end{array}$ \\
\hline sVCAM-1 & $0.970(0.330-1.610)$ & $\begin{array}{l}0.160(0.094-0.220) \\
(<0.0001)\end{array}$ & $\begin{array}{l}0.130(0.052-0.002) \\
(0.0009)\end{array}$ & $\begin{array}{l}0.430(0.170-0.680) \\
(0.0010)\end{array}$ & $\begin{array}{l}0.320(0.120-0.510) \\
(0.0015)\end{array}$ \\
& $(0.0029)$ & $9.591(5.289-13.982)$ & $6.477(2.962-9.994)$ & $17.695(-4.989-40.378)$ & $15.220(7.567-22.872)$ \\
MMP-3 & $52.712(34.933-70.492)$ & $(<0.0001)$ & $(0.0003)$ & $(0.1263)$ & $(<0.0001)$ \\
& $(<0.0001)$ & $2.520(1.400-3.630)(<0.0001)$ & $2.270(0.970-3.570)$ & $6.510(3.250-9.780)$ & $5.980(2.480-9.480)$ \\
SICAM-1 & $16.120(3.020-29.220)$ & $(0.0006)$ & $(<0.0001)$ & $(0.0008)$ \\
& $(0.0159)$ & $0.200(0.110-0.300)$ & $0.140(0.070-0.220)$ & $0.610(0.430-0.800)$ & $0.790(0.400-1.190)$ \\
TIMP-1 & $1.470(0.200-2.740)$ & $(<0.0001)$ & $(0.0002)$ & $(<0.0001)$ & $(<0.0001)$ \\
& $(0.0228)$ & $0.100(0.047-0.140)$ & $0.070(0.013-0.130)$ & $0.250(0.120-0.370)$ & $0.210(0.130-0.300)$ \\
VEGF & $0.076(-0.310-0.460)$ & $(0.0001)$ & $(0.0160)$ & $(0.0001)$ & $(<0.0001)$ \\
& $(0.6985)$ & $0.044(-0.130-0.220)$ & $0.036(-0.120-0.190)$ & $0.310(-0.210-0.820)$ & $0.420(0.073-0.760)$ \\
MCP-1 & $0.470(-0.670-1.610)$ & $(0.6207)$ & $(0.6529)$ & $(0.2410)$ & $(0.0175)$ \\
\hline
\end{tabular}

Estimates (Est $\times 10^{-2}$ ) of regression coefficient (Beta estimate), 95\% confidence intervals, and raw $p$ values are listed in the table; those meeting FDR $<0.05$ are italicized

Abbreviations: KL Kellgren-Lawrence; JSN joint space narrowing; OST osteophyte; PAS pain, aching and stiffness of knee; $p v a l p$ value; $C I$ confidence interval; sVCAM1 soluble vascular cell adhesion molecule 1; MMP-3 matrix metalloproteinase-3; sICAM-1 soluble intracellular adhesion molecule 1; TIMP-1 tissue inhibitor of metallopeptidase inhibitor 1; VEGF vascular endothelial growth factor; MCP-1 monocyte chemoattractant protein 1 
Table 3 Correlations of synovial fluid RBM biomarkers with known osteoarthritis progression biomarkers

\begin{tabular}{|c|c|c|c|c|c|c|}
\hline \multirow{2}{*}{$\begin{array}{l}\text { OA Progression } \\
\text { Biomarkers }\end{array}$} & \multicolumn{6}{|c|}{ Subset of synovial fluid RBM biomarkers associated with features of knee osteoarthritis* } \\
\hline & $\begin{array}{l}\text { sVCAM-1 } \\
\text { r (95\% Cl) } \\
\text { (pval) }\end{array}$ & $\begin{array}{l}\text { MMP-3 } \\
\text { r ( } 95 \% \text { Cl) } \\
\text { (pval) }\end{array}$ & $\begin{array}{l}\text { sICAM-1 } \\
r(95 \% \mathrm{Cl}) \\
\text { (pval) }\end{array}$ & $\begin{array}{l}\text { TIMP-1 } \\
\text { r (95\% Cl) } \\
\text { (pval) }\end{array}$ & $\begin{array}{l}\text { VEGF } \\
r(95 \% \text { Cl) } \\
\text { (pval) }\end{array}$ & $\begin{array}{l}\text { MCP-1 } \\
r(95 \% \mathrm{Cl}) \\
\text { (pval) }\end{array}$ \\
\hline$\overline{C D 14}$ & $\begin{array}{l}0.86(0.69-0.94) \\
(<0.0001)\end{array}$ & $\begin{array}{l}0.77(0.50-0.91) \\
(<0.0001)\end{array}$ & $\begin{array}{l}0.84(0.64-0.94) \\
(<0.0001)\end{array}$ & $\begin{array}{l}0.88(0.72-0.95) \\
(<0.0001)\end{array}$ & $\begin{array}{l}0.90(0.76-0.96) \\
(<0.0001)\end{array}$ & $\begin{array}{l}0.50(0.08-0.76) \\
(0.016)\end{array}$ \\
\hline CD163 & $\begin{array}{l}0.80(0.56-0.92) \\
(<0.0001)\end{array}$ & $\begin{array}{l}0.78(0.51-0.91) \\
(<0.0001)\end{array}$ & $\begin{array}{l}0.70(0.37-0.88) \\
(0.0004)\end{array}$ & $\begin{array}{l}0.85(0.66-0.94) \\
(<0.0001)\end{array}$ & $\begin{array}{l}0.75(0.44-0.90) \\
(0.0001)\end{array}$ & $\begin{array}{l}0.43(-0.02-0.73) \\
(0.046)\end{array}$ \\
\hline Neutrophil Elastase & $\begin{array}{l}0.88(0.68-0.96) \\
(<0.0001)\end{array}$ & $\begin{array}{l}0.88(0.68-0.96) \\
(<0.0001)\end{array}$ & $\begin{array}{l}0.87(0.64-0.96) \\
(<0.0001)\end{array}$ & $\begin{array}{l}0.89(0.71-0.97) \\
(<0.0001)\end{array}$ & $\begin{array}{l}0.62(0.16-0.86) \\
(0.008)\end{array}$ & $\begin{array}{l}0.14(-0.40-0.61) \\
(0.581)\end{array}$ \\
\hline
\end{tabular}

*As shown in Table 2; italicized $p$ values pass FDR $<0.05 ; r=$ repeated measures correlation coefficient by Bland and Altman method implemented in rmcorr Abbreviations: RBM Rules Based Medicine, pval $p$ value, $C I$ confidence interval, sVCAM-1 soluble vascular cell adhesion molecule 1, MMP-3 matrix metalloproteinase3, sICAM-1 soluble intracellular adhesion molecule 1, TIMP-1 tissue inhibitor of metallopeptidase inhibitor 1, VEGF vascular endothelial growth factor, MCP-1 monocyte chemoattractant protein 1

of one plasma biomarker, VEGF, correlated with its corresponding SF concentrations (Spearman's rho $p$ value $\leq$ 0.05 , Additional file 1). Interestingly, plasma concentrations of VEGF also correlated with SF concentrations (averaged across both knees) of the other five inflammation associated biomarkers (sICAM-1, MCP-1, MMP-3, TIMP-1, and sVCAM-1). In addition, plasma MMP-3 correlated with SF concentrations of sVCAM-1. SF concentrations of VEGF, MMP-3, and TIMP-1 were all statistically significantly higher than the corresponding plasma concentrations (Additional file 2). Taken together, these results suggest that plasma VEGF may originate from the joint and reflect SF concentrations.

\section{Interactions of biomarkers associated with severity of $O A$ inflammation, structural features, and symptoms}

We utilized STRING [26] to generate a functional protein association network for the six SF biomarkers (MMP-3, sVCAM-1, SICAM-1, VEGF, TIMP-1, and MCP-1) in this study with significant associations with etarfolatide (inflammation), KL (radiographic severity), and OA symptom scores. We added SF CD14, SF CD163, and SF neutrophil elastase to the model as biomarker surrogates for inflammation as we previously showed them to be strongly associated with the presence of folate receptor-positive cells in knee joints using etarfolatide imaging, strongly predictive of knee OA progression $[8,16]$, and correlated with the OA-related RBM markers of the final panel. Relevant biological pathways strongly associated with these nine biomarkers include leukocyte migration and extracellular matrix organization (Fig. 1). This plot is consistent with these biomarkers functioning both as extracellular signaling molecules and as effectors of OA progression.

\section{Discussion}

MMP-3, sVCAM-1, sICAM-1, VEGF, TIMP-1, and MCP-1 were all associated with synovial inflammation by etarfolatide imaging, radiographic OA severity, and/or OA symptoms. Although soluble VCAM-1, sICAM-1, and VEGF have no known intrinsic ability to cause cartilage loss, they were strongly associated with severity of cartilage loss based on JSN and macrophage and neutrophil markers (SF CD14, SF CD163, and SF elastase) that we found previously to be associated with OA progression $[8,16]$. Etarfolatide imaging, indicating the presence of activated macrophages and neutrophils in the synovial tissue [8], provided additional in vivo evidence for synovial inflammation that was positively associated with SF biomarkers MMP-3 and sVCAM-1. These results are consistent with the inflammation and arthritis promoting roles of these molecules (summarized in Fig. 2) [9, 11, 15, 16, 27-37]. In particular, VCAM-1 is expressed by all cell types of the joint organ, chondrocytes, synovial fibroblasts, and adipocytes. Because VCAM-1 binds leukocytes [35], soluble VCAM-1 serves as a chemotactic stimulus for macrophages [36], and DAMPS and MCP-1 serve as chemotactic stimuli for macrophages and neutrophils [38], thereby providing direct means for macrophages and neutrophils to home to the joint to promote cartilage degradation.

Of the six biomarkers, MMP-3, VEGF, and TIMP-1 were more abundant in SF than plasma supporting a joint tissue origin. The finding that SF, but not plasma biomarkers, correlated with OA severity outcomes, taken together with existing literature on these analytes in OA, further supports the concept that these markers are specific to local disease-related phenomena in the joint organ [39]. For instance, MMP-3, a well-known collagen degrading protease associated with OA progression [29], is known to contribute to cartilage breakdown with the generation of DAMPs $[40,41]$. These DAMPs can directly activate macrophages and neutrophils [33] and increase synovial inflammation through toll-like receptor signaling $[34,40]$. VEGF is a signal protein of angiogenesis that can increase inflammation through creation of blood vessels capable of leukocyte recruitment [27, 28]. VEGF injected into the temporomandibular joint increased MMP-9, 


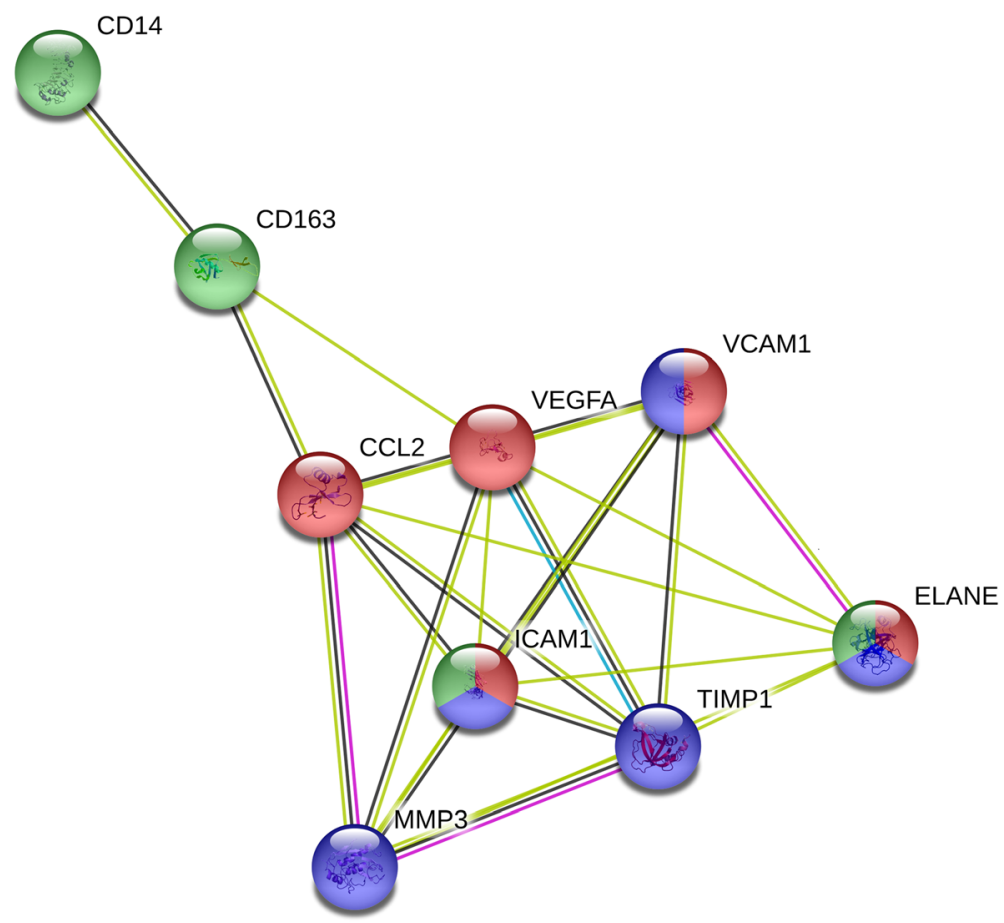

Fig. 1 STRING plot showing functional biomarker interrelationships. Depicted relationships represent biomarkers with significant associations with OA inflammation, radiographic OA, and OA symptoms analyzed using the STRING v10.5 database. The colors of the spheres correspond to the biological processes in which a particular biomarker is involved. Sphere color key: leukocyte migration (red), extracellular matrix organization (blue), and inflammatory response (green). Joining string color key (corresponding to origin of data used for STRING database): curated databases (blue), experimentally determined (pink), textmining (yellow), and co-expression (black). Abbreviations: CD, cluster of differentiation 14; CD163, cluster of differentiation 163; CCL2 (also referred to as MCP-1 or monocyte chemoattractant protein 1), C-C chemokine motif 2 vascular cell adhesion molecule 1; ELANE, neutrophil elastase; ICAM-1, intracellular adhesion molecule 1; MMP-3, matrix metalloproteinase-3; TIMP-1, tissue inhibitor of metallopeptidase inhibitor 1; VEGF, vascular endothelial growth factor

MMP-13, the initiation of OA, and cartilage loss [42]. VEGF inhibition, in surgically induced (destabilization of medial meniscus) OA, reduced OA progression [43]. VEGF also acts as a chemoattractant and activator of macrophages [44]. Once macrophages are recruited to the joint, they have the ability to produce more VEGF and promote further angiogenesis, symptoms [45], and synovitis that will facilitate macrophage recruitment and perpetuate joint inflammation [29].

Although the hallmarks of osteoarthritis, OA pain, aching, and stiffness, are highly heterogeneous, a major contributor to OA symptoms is synovitis [29]. It is therefore understandable that synovial fluid biomarkers shown here (sVCAM-1, MMP-3, sICAM-1, VEGF, TIMP-1) and previously (CD14) to be associated with synovial inflammation (as reflected by etarfolatide imaging scores) [16] were also associated with joint pain, aching, and stiffness. These markers may therefore have value as indicators of a symptomatic inflammatory OA endotype. These results are in agreement with previous studies showing that SVCAM-1 and SICAM-1 are associated with synovitis $[36,46]$. Moreover, VEGF can also lead to cartilage vascularization at sites that subsequently form osteophytes [47]; osteophytes are a feature of OA known to contribute to symptoms [15].

Limitations of this study include the small cohort size, especially in comparison to the number of outcomes measured. However, to mitigate this limitation, multiple measures correction was performed by adjusting $p$ values using the Benjamini-Hochberg false discovery rate [24] method. Due to the cross-sectional analysis and absence of longitudinal data, causality of biomarkers with OA progression could not be inferred. Although we do not have longitudinal data, several of these biomarkers have face validity for involvement in OA progression based on the literature including VEGF, ICAM1, VCAM1, and MMP3 [6, 31, 48-51]. When direct aspiration of SF failed, low volume saline lavage was performed. Using both direct and lavage SF in this study is both a strength and a limitation. On the one hand, this is a strategy that allows potential evaluation of the highest number of knees, even less inflamed ones without appreciable SF; on the other hand, the knees requiring lavage tend to be less 


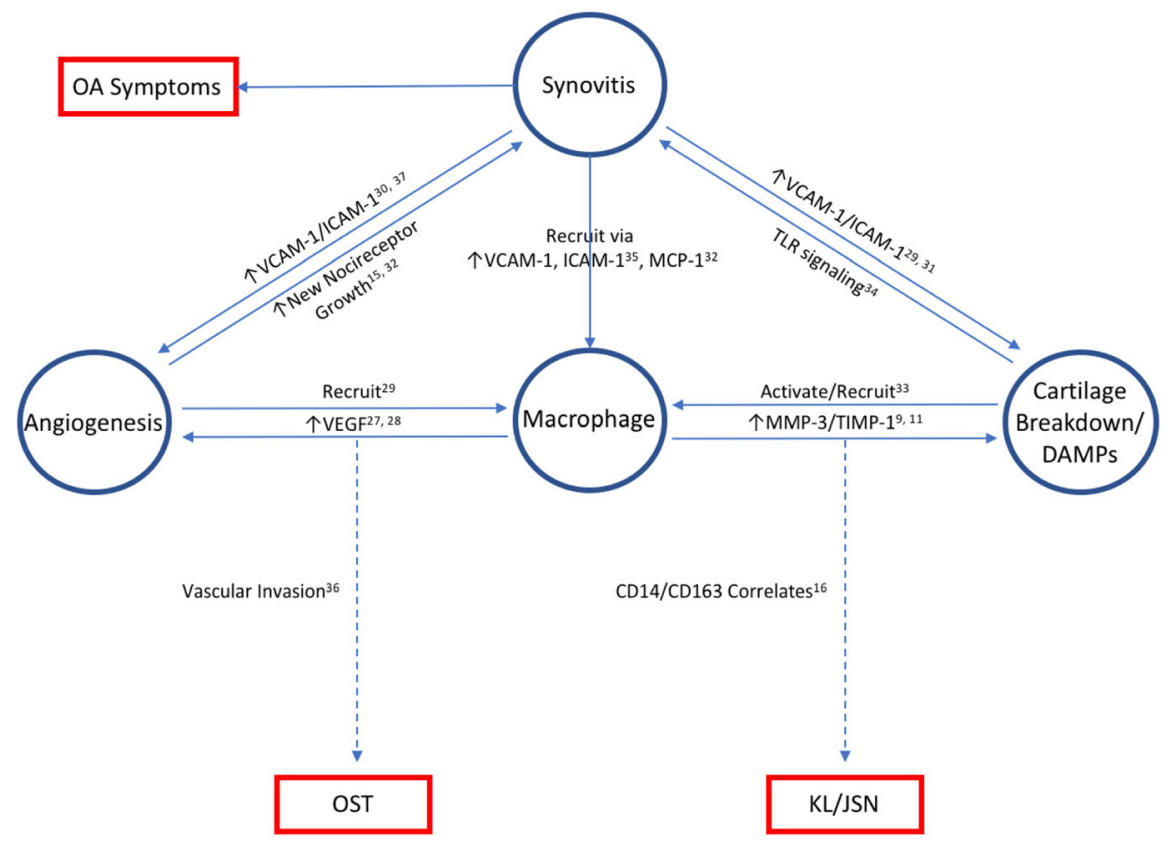

Fig. 2 Inflammatory OA endotype based on synovial fluid biomarkers. This plot conceptualizes our data in the context of the current understanding of inflammation in OA. Abbreviations: OA, osteoarthritis; DAMPs, disease-associated molecular patterns; VCAM-1, vascular cell adhesion molecule 1; MMP3, matrix metalloproteinase-3; ICAM-1, intracellular adhesion molecule 1; TLR, toll-like receptor; TIMP-1, tissue inhibitor of metallopeptidase inhibitor 1; VEGF, vascular endothelial growth factor; MCP-1, monocyte chemoattractant protein 1; KL, Kellgren-Lawrence; JSN, joint space narrowing; OST, osteophyte; NHANES, national health and nutrition examination survey measure of OA symptoms (pain, aching, stiffness)

inflamed, having lower inflammatory biomarker concentrations that are even lower with lavage. As expected, more biomarker concentrations from lavage samples were below lower limits of detection of the inflammation map multiplex assays. Nevertheless, we were partially able to overcome these challenges with biomarker selection criteria, the well-established urea correction method [23] and a well-established imputation methodology. Although only 17 of 47 SF biomarkers passed our inclusion criteria for statistical analysis, the biological credibility of the results attests to the viability of this strategy.

\section{Conclusions}

In summary, this study provides support for an inflammatory knee OA endotype characterized by the presence in the synovium of activated macrophages and neutrophils and their association with SF biomarkers of inflammation and angiogenesis. These data support a highly integrated process with VEGF, a biomarker of angiogenesis [37], increasing expression of MMPs and inflammation, based on markers of vascular adhesion, sVCAM-1 and sICAM-1, correlated with synovitis [36]. This biomarker profile may assist in identifying a specific subgroup of patients for treatments modulating inflammation and activated macrophages and neutrophils.

\section{Additional files}

Additional file 1: Correlation of biomarkers in plasma with synovial fluid. SF biomarkers were correlated to corresponding plasma biomarkers using Spearman correlation. (DOCX $16 \mathrm{~kb}$ )

Additional file 2: Wilcoxon signed ranks for SF vs. plasma. Wilcoxon signed-rank statistic shows whether the biomarker was higher in SF or plasma. (DOCX $13 \mathrm{~kb}$ )

\section{Abbreviations}

A2M: Alpha-2-Macroglobulin; AAT: Alpha-1-Antitrypsin; B2M: Beta-2Microglobulin; C3: Complement C3; CV: Coefficient of Variation; DAMPs: Damage-associated molecule patterns; FRTN: Ferritin; GEE: Generalized estimating equations; ICAM-1: Intercellular adhesion molecule 1; IL-1 ra: Interleukin-1 receptor antagonist; IQR: Interquartile range; JSN: Joint space narrowing; KL: Kellgren-Lawrence; LLOD: Lower limit of detection; MCP-1: Monocyte chemotactic protein 1; MMP: Matrix metalloproteinase; MMP-3: Matrix metalloproteinase-3; MMP-9: Matrix metalloproteinase-9; OA: Osteoarthritis; OST: Osteophyte; PARs: Proteinaseactivated receptors; SCF: Stem cell factor; SF: Synovial fluid; TIMP-1: Tissue inhibitor of metalloproteinases 1; ULOD: Upper limit of detection; VCAM1: Vascular cell adhesion molecule-1; VDBP: Vitamin D-binding protein; VEGF: Vascular endothelial growth factor

\section{Acknowledgements}

We wish to acknowledge Dr. Peter Mitchell for his assistance with the study design and funding of the original etarfolatide cohort study.

\section{Funding}

This study was funded in part by NIH/NIA Claude D. Pepper OAIC AG028716. The original cohort and biomarker analyses were funded by Eli Lilly and Co. Dr. Peter Mitchell, then at Eli Lilly and Co, assisted with the design of the original study. The funding bodies had no role in the collection, analysis or interpretation of data or in writing the manuscript. 


\section{Availability of data and materials}

The datasets used and/or analyzed during the current study are available from the corresponding author on reasonable request.

\section{Authors' contributions}

CAH drafted the manuscript and assisted with statistical analyses. JLH was involved with the study design, provided sample handling, and assisted with statistical analyses and data interpretation. MFH generated the neutrophil elastase data. YJL performed and supervised all the statistical analyses. VBK designed and supervised all aspects of the study. All authors participated in manuscript editing. All authors read and approved the final manuscript.

\section{Ethics approval and consent to participate}

This clinical investigation was conducted according to Declaration of Helsinki principles, with the approval of the Duke University Medical Center Institutional Review Board. Written informed consent was received from participants prior to inclusion in the study.

\section{Consent for publication}

Not applicable.

\section{Competing interests}

The authors declare that they have no competing interests.

\section{Publisher's Note}

Springer Nature remains neutral with regard to jurisdictional claims in published maps and institutional affiliations.

\section{Author details}

'Duke Molecular Physiology Institute, Duke University School of Medicine, Box 104775, 300 North Duke St, Durham, NC 27701, USA. ${ }^{2}$ Department of Biostatistics and Bioinformatics, Duke University School of Medicine, Durham, NC, USA. ${ }^{3}$ Department of Medicine, Duke University School of Medicine, Durham, NC, USA.

Received: 15 February 2019 Accepted: 22 May 2019

Published online: 13 June 2019

\section{References}

1. Walther M, Harms H, Krenn V, Radke S, Faehndrich T-P, Gohlke F. Correlation of power Doppler sonography with vascularity of the synovial tissue of the knee joint in patients with osteoarthritis and rheumatoid arthritis. Arthritis Rheum. 2001;44(2):331-8.

2. Abraham AM, Goff I, Pearce MS, Francis RM, Birrell F. Reliability and validity of ultrasound imaging of features of knee osteoarthritis in the community. BMC Musculoskelet Disord. 2011;12:70.

3. Loeuille D, Chary-Valckenaere I, Champigneulle J, Rat A-C, Toussaint F, Pinzano-Watrin A, et al. Macroscopic and microscopic features of synovial membrane inflammation in the osteoarthritic knee: correlating magnetic resonance imaging findings with disease severity. Arthritis Rheum. 2005; 52(11):3492-501

4. Østergaard M, Stoltenberg M, Løvgreen-Nielsen P, Volck B, Jensen Claus $H$, Lorenzen I. Magnetic resonance imaging-determined synovial membrane and joint effusion volumes in rheumatoid arthritis and osteoarthritis. Comparison with the macroscopic and microscopic appearance of the synovium. Arthritis Rheum. 2005;40(10):1856-67.

5. Yusuf E, Kortekaas MC, Watt I, Huizinga TWJ, Kloppenburg M. Do knee abnormalities visualised on MRI explain knee pain in knee osteoarthritis? A systematic review. Ann Rheum Dis. 2011;70(1):60.

6. Atukorala I, Kwoh CK, Guermazi A, Roemer FW, Boudreau RM, Hannon MJ, et al. Synovitis in knee osteoarthritis: a precursor of disease? Ann Rheum Dis. 2016;75(2):390

7. Kraus VB, McDaniel G, Huebner JL, Stabler TV, Pieper CF, Shipes SW, et al. Direct in vivo evidence of activated macrophages in human osteoarthritis. Osteoarthr Cartil. 2016;24(9):1613-21.

8. Hsueh MF, Lu Y, Wellman SS, Bolognesi MP, Kraus VB. Functional folate receptor cell-associated inflammatory cytokines predict the progression of knee osteoarthritis. Osteoarthr Cartil. 2018;26:S121-S2.

9. Blom AB, van Lent PLEM, Holthuysen AEM, van der Kraan PM, Roth J, van Rooijen N, et al. Synovial lining macrophages mediate osteophyte formation during experimental osteoarthritis. Osteoarthr Cartil. 2004;12(8):627-35.
10. Huang W-C, Sala-Newby GB, Susana A, Johnson JL, Newby AC. Classical macrophage activation up-regulates several matrix metalloproteinases through mitogen activated protein kinases and nuclear factor-kB. PLoS One. 2012;7(8):e42507.

11. Korkmaz B, Horwitz MS, Jenne DE, Gauthier F. Neutrophil elastase, proteinase 3, and cathepsin $\mathrm{G}$ as therapeutic targets in human diseases. Pharmacol Rev. 2010;62(4):726.

12. Muley MM, Krustev E, Reid AR, McDougall JJ. Prophylactic inhibition of neutrophil elastase prevents the development of chronic neuropathic pain in osteoarthritic mice. J Neuroinflammation. 2017;14(1):168.

13. Zhou J, Perelman JM, Kolosov VP, Zhou X. Neutrophil elastase induces MUC5AC secretion via protease-activated receptor 2. Mol Cell Biochem. 2013;377(1):75-85.

14. Russell FA, McDougall JJ. Proteinase activated receptor (PAR) involvement in mediating arthritis pain and inflammation. Inflamm Res. 2009;58(3):119-26.

15. Huesa C, Ortiz AC, Dunning L, McGavin L, Bennett L, McIntosh K, et al. Proteinase-activated receptor 2 modulates OA-related pain, cartilage and bone pathology. Annals of the Rheumatic Diseases. 2016.

16. Daghestani HN, Pieper CF, Kraus VB. Soluble macrophage biomarkers indicate inflammatory phenotypes in patients with knee osteoarthritis. Arthritis Rheumatol. 2015;67(4):956-65.

17. Huebner JL, Haraden C, Li YJ, Kraus VB. Biomarkers of macrophageassociated inflammatory pathways are associated with OA symptoms and radiographic disease. Osteoarthr Cartil. 2018;26:S42.

18. Kellgren JH, Lawrence JS. Radiological assessment of osteo-arthrosis. Ann Rheum Dis. 1957;16(4):494-502.

19. Davis MA, Ettinger WH, Neuhaus JM. Obesity and osteoarthritis of the knee: evidence from the National Health and Nutrition Examination Survey (NHANES I). Semin Arthritis Rheum. 1990;20(3 Suppl 1):34-41.

20. Charles HC, Kraus VB, Ainslie M. Hellio Le Graverand-Gastineau MP. Optimization of the fixed-flexion knee radiograph. Osteoarthr Cartil. 2007; 15(11):1221-4.

21. McDaniel G, Renner JB, Sloane R, Kraus VB. Association of knee and ankle osteoarthritis with physical performance. Osteoarthr Cartil. 2011;19(6):634-8.

22. Altman RD, Gold GE. Atlas of individual radiographic features in osteoarthritis, revised. Osteoarthritis Cartilage. 2007;15 Suppl A:A1-56.

23. Kraus VB, Stabler TV, Kong SY, Varju G, McDaniel G. Measurement of synovial fluid volume using urea. Osteoarthr Cartil. 2007;15(10):1217-20.

24. Benjamini Y, Hochberg Y. Controlling the false discovery rate: a practical and powerful approach to multiple testing. J R Stat Soc Ser B. 1995;57:289-300.

25. Bland JM, Altman DG. Calculating correlation coefficients with repeated observations: part 1--correlation within subjects. BMJ. 1995;310(6977):446.

26. Szklarczyk D, Franceschini A, Wyder S, Forslund K, Heller D, Huerta-Cepas J, et al. STRING v10: protein-protein interaction networks, integrated over the tree of life. Nucleic Acids Res. 2015;43(Database issue):D447-D52.

27. Pufe $T$, Petersen $W$, Tillmann B, Mentlein R. The splice variants VEGF121 and VEGF189 of the angiogenic peptide vascular endothelial growth factor are expressed in osteoarthritic cartilage. Arthritis Rheum. 2001;44(5):1082-8.

28. Pfander D, Körtje D, Zimmermann R, Weseloh G, Kirsch T, Gesslein M, et al. Vascular endothelial growth factor in articular cartilage of healthy and osteoarthritic human knee joints. Ann Rheum Dis. 2001;60(11):1070,

29. Sellam J, Berenbaum F. The role of synovitis in pathophysiology and clinical symptoms of osteoarthritis. Nat Rev Rheumatol. 2010;6:625.

30. Ramos TN, Bullard DC, Barnum SR. ICAM-1: isoforms and phenotypes. J Immunol. 2014;192(10):4469-74.

31. Schett G, Kiechl S, Bonora E, Zwerina J, Mayr A, Axmann R, et al. Vascular cell adhesion molecule 1 as a predictor of severe osteoarthritis of the hip and knee joints. Arthritis Rheum. 2009;60(8):2381-9.

32. Miotla Zarebska J, Chanalaris A, Driscoll C, Burleigh A, Miller RE, Malfait AM, et al. CCL2 and CCR2 regulate pain-related behaviour and early gene expression in post-traumatic murine osteoarthritis but contribute little to chondropathy. Osteoarthr Cartil. 2017;25(3):406-12.

33. Huang H, Tohme S, Al-Khafaji Ahmed B, Tai S, Loughran P, Chen L, et al. Damage-associated molecular pattern-activated neutrophil extracellular trap exacerbates sterile inflammatory liver injury. Hepatology. 2015;62(2):600-14.

34. Sokolove J, Lepus CM. Role of inflammation in the pathogenesis of osteoarthritis: latest findings and interpretations. Therapeutic Adv Musculoskeletal Dis. 2013:5(2):77-94.

35. Oertli B, Beck-Schimmer B, Fan X, Wüthrich RP. Mechanisms of hyaluronaninduced up-regulation of ICAM-1 and VCAM-1 expression by murine kidney tubular epithelial cells: hyaluronan triggers cell adhesion molecule 
expression through a mechanism involving activation of nuclear factor- $\mathrm{KB}$ and activating protein-1. J Immunol. 1998;161(7):3431.

36. Cook-Mills JM, Marchese ME, Abdala-Valencia H. Vascular cell adhesion molecule-1 expression and signaling during disease: regulation by reactive oxygen species and antioxidants. Antioxid Redox Signal. 2011;15(6):1607-38.

37. Koh TJ, DiPietro LA. Inflammation and wound healing: the role of the macrophage. Expert Rev Mol Med. 2011;13:e23.

38. Petri B, Sanz M-J. Neutrophil chemotaxis. Cell and Tissue Research. 2018;371:425

39. Zhang W, Likhodii S, Aref-Eshghi E, Zhang Y, Harper PE, Randell E, et al. Relationship between blood plasma and synovial fluid metabolite concentrations in patients with osteoarthritis. J Rheumatol. 2015;42(5):859.

40. Foell D, Wittkowski H, Roth J. Mechanisms of disease: a 'DAMP' view of inflammatory arthritis. Nat Clin Pract Rheumatol. 2007;3:382.

41. Zhang X, Mosser DM. Macrophage activation by endogenous danger signals. J Pathol. 2008;214(2):161-78

42. Shen $P$, Jiao Z, Zheng JS, Xu WF, Zhang SY, Qin A, et al. Injecting vascular endothelial growth factor into the temporomandibular joint induces osteoarthritis in mice. Sci Rep. 2015;5:16244

43. Nagao M, Hamilton JL, Kc R, Berendsen AD, Duan X, Cheong CW, et al. Vascular endothelial growth factor in cartilage development and osteoarthritis. Sci Rep. 2017:7(1):13027.

44. Barleon B, Sozzani S, Zhou D, Weich HA, Mantovani A, Marme D. Migration of human monocytes in response to vascular endothelial growth factor (VEGF) is mediated via the VEGF receptor flt-1. Blood. 1996;87(8):3336.

45. Haywood L, McWilliams DF, Pearson Cl, Gill SE, Ganesan A, Wilson D, et al. Inflammation and angiogenesis in osteoarthritis. Arthritis Rheum. 2003;48(8):2173-7.

46. Neogi T, Guermazi A, Roemer F, Nevitt Michael C, Scholz J, Arendt-Nielsen L, et al. Association of Joint Inflammation with pain sensitization in knee osteoarthritis: the multicenter Osteoarthritis Study. Arthritis Rheumatol. 2015 68(3):654-61.

47. Hashimoto S, Creighton-Achermann L, Takahashi K, Amiel D, Coutts RD, Lotz M. Development and regulation of osteophyte formation during experimental osteoarthritis. Osteoarthr Cartil. 2002;10(3):180-7.

48. Wojdasiewicz P, Poniatowski ŁA, Szukiewicz D. The role of inflammatory and anti-inflammatory cytokines in the pathogenesis of osteoarthritis. Mediat Inflamm. 2014;2014.

49. Hamilton JL, Nagao M, Levine BR, Chen D, Olsen BR, Im HJ. Targeting VEGF and its receptors for the treatment of osteoarthritis and associated pain. J Bone Miner Res. 2016;31(5):561459.

50. Mathiessen A, Conaghan PG. Synovitis in osteoarthritis: current understanding with therapeutic implications. Arthritis Res Ther. 2017;19(1):18

51. Yuan Q, Sun L, Li JJ, An CH. Elevated VEGF levels contribute to the pathogenesis of osteoarthritis. BMC Musculoskelet Disord. 2014;15:437.

Ready to submit your research? Choose BMC and benefit from:

- fast, convenient online submission

- thorough peer review by experienced researchers in your field

- rapid publication on acceptance

- support for research data, including large and complex data types

- gold Open Access which fosters wider collaboration and increased citations

- maximum visibility for your research: over $100 \mathrm{M}$ website views per year

At $\mathrm{BMC}$, research is always in progress.

Learn more biomedcentral.com/submissions 